\title{
BIOPROCESSO DE PRODUÇÃO DO ANTITUMORAL HOLOMICINA POR STREPTOMYCES CLAVULIGERUS
}

\author{
A. S. BAPTISTA ${ }^{1}$, A. P. CAVALLIERI ${ }^{1}$, C. A. LEITE $^{1}$, A. J. G. CRUZ ${ }^{2}$ e M. L. G. C. ARAUJO ${ }^{1}$ \\ ${ }^{1}$ Universidade Estadual Paulista, Departamento de Bioquímica e Tecnologia Química, Instituto de \\ Química, Araraquara - SP \\ ${ }^{2}$ Universidade Federal de São Carlos, Departamento de Engenharia Química, São Carlos - SP \\ E-mail para contato: mlaraujo@iq.unesp.br
}

\begin{abstract}
RESUMO - Streptomyces clavuligerus produz vários biocompostos de uso terapêutico, como os beta-lactâmicos ácido clavulânico e cefamicina $\mathrm{C}$, e os não beta-lactâmicos holomicina e tunicamicina. Holomicina é conhecida por inibir a síntese de RNA polimerase de bactérias resistentes a rifamicina e é produzida em baixas concentrações (6 a $8 \mathrm{mg} \cdot \mathrm{L}^{-1}$ ) pela cepa selvagem (ATCC 27064) sob condições favoráveis à produção de beta-lactâmicos. Cultivos em biorreator convencional operado em batelada mostraram que a combinação de maltose e lisina promoveu a produção de cefamicina $\mathrm{C}$ e ácido clavulânico (90 a $100 \mathrm{mg} \cdot \mathrm{L}^{-1}$ ), sem produção de holomicina, e a mesma combinação (maltose e lisina) adicionada de glutamato estimulou a produção de holomicina (95 a $110 \mathrm{mg} \cdot \mathrm{L}^{-1}$ ), com produção de cefamicina $\mathrm{C}$ ou ácido clavulânico cerca de $65 \%$ menor para ambos. Os dados obtidos permitiram estimar parâmetros cinéticos e estequiométricos dos processos por meio de modelagem e simulação.
\end{abstract}

\section{INTRODUÇÃO}

A espécie Streptomyces clavuligerus foi inicialmente descrita como produtora dos importantes compostos beta-lactâmicos cefamicina $\mathrm{C}$ (CefC), utilizada na produção de antibióticos semi sintéticos bioativos inclusive contra bactérias anaeróbias, e ácido clavulânico (AC), um potente inibidor de beta-lactamases. Além de produzir mais de vinte clavamas, linhagens desta espécie também produzem bioativos não beta-lactâmicos, como holomicina (Hol) e tunicamicina (LIRAS e MARTÍN, 2006). Hol pertence à classe das pirrotinas, compostos que apresentam atividade antimicrobiana e antitumoral, sendo conhecida como precursor de um inibidor da síntese de RNA polimerase em bactérias resistentes à rifamicina (OLIVA et al., 2001). Foi isolada de algumas espécies de Streptomyces e caracterizada quimicamente em meados da década de 1960, embora sua produção tenha sido atribuída a $S$. clavuligerus apenas vinte anos depois (KENING e READING, 1979). Pouco se sabe sobre a origem biossintética de Hol ou de outras ditiolopirrolonas, como aureotricina e xenorhabdinas. Apenas uma rota biossintética para Hol foi proposta, com base em ferramentas da bioinformática, havendo ainda relatos sobre a identificação e a caracterização do agrupamento de genes responsável pela sua biossíntese (LI e WALSH, 2010). Quanto à biossíntese do composto por S. clavuligerus, há escassos estudos comparativos de capacidades produtivas e diferenças genéticas observadas entre a linhagem selvagem e mutantes melhores produtores (DE LA FUENTE et al., 2002; NÁRDIZ et al., 2011). Dados da literatura sempre associaram a produção de quantidades desprezíveis de Hol à linhagem selvagem $S$. clavuligerus ATCC 27064. Por outro lado, cultivos em glicerol ou amido adicionados dos 
aminoácidos lisina, ácido alfa-aminoadípico, arginina e/ou ornitina, ou da diamina 1,3 diaminopropano, promovem produções significativas de compostos beta-lactâmicos, como CefC ou AC, com destaque para este último (DOMINGUES et al., 2010; LEITE et al., 2013). No presente trabalho, a produção de biocompostos por $S$. clavuligerus foi investigada em dois meios quimicamente definidos contendo diferentes fontes de carbono e nitrogênio. Os dados experimentais obtidos em cultivos em batelada em biorreator convencional em escala de bancada foram comparados por meio de estudos de modelagem e simulação, com a obtenção de parâmetros estatisticamente significativos.

\section{MATERIAL E MÉTODOS}

Suspensão de esporos $\left(10^{8}\right.$ esporos $\left.\cdot \mathrm{mL}^{-1}\right)$ de Streptomyces clavuligerus (ATCC 27064), conservada a $-80^{\circ} \mathrm{C}$ em solução crioprotetora (glicerol a $20 \% \mathrm{v} \cdot \mathrm{v}^{-1}$ ), foi utilizada como inóculo inicial dos cultivos submersos. Os esporos foram germinados em meio contendo $\left(\mathrm{g} \cdot \mathrm{L}^{-1}\right)$ : triptona $(5,0)$, extrato de levedura $(3,0)$, extrato de malte $(10)$ e o tampão biológico ácido 3-(N-morfolino) propanossulfônico (MOPS) (21); pH ajustado em 6,8 \pm 0,1. O inóculo principal foi preparado em meio contendo $\left(\mathrm{g} \cdot \mathrm{L}^{-1}\right)$ : maltose $(10)$, lisina $(4,0)$, glutamato $(5,5)$, extrato de levedura $(1,0)$, $\mathrm{K}_{2} \mathrm{HPO}_{4}(0,80), \mathrm{MgSO}_{4} 7 \mathrm{H}_{2} \mathrm{O}(0,75), \operatorname{MOPS}(21), 10 \mathrm{~mL} \cdot \mathrm{L}^{-1}$ de solução de sais contendo $\left(\mathrm{g} \cdot \mathrm{L}^{-1}\right)$ $\mathrm{MnCl}_{2} \cdot 4 \mathrm{H}_{2} \mathrm{O}(1,0), \mathrm{FeSO}_{4} \cdot 7 \mathrm{H}_{2} \mathrm{O}(1,0), \mathrm{ZnSO}_{4} \cdot 7 \mathrm{H}_{2} \mathrm{O}(1,0)$, e $1,0 \mathrm{~mL} \cdot \mathrm{L}^{-1}$ de solução de elementos traços contendo $(\mathrm{g} / \mathrm{L}) \mathrm{CuSO}_{4} \cdot 5 \mathrm{H}_{2} \mathrm{O}(0,49), \mathrm{CoCl}_{2}(0,28)$ e $\mathrm{Na}_{2} \mathrm{MoO}_{4}(0,15) ; \mathrm{pH}$ ajustado em $7,2 \pm$ 0,1 . Foram utilizados dois meios de produção quimicamente definidos, contendo basicamente $\left(\mathrm{g} \cdot \mathrm{L}^{-1}\right)$ : maltose $(10), \mathrm{K}_{2} \mathrm{HPO}_{4}(1,75), \mathrm{MgSO}_{4} 7 \mathrm{H}_{2} \mathrm{O}(0,75), \mathrm{CaCl}(0,20), \mathrm{NaCl}(2,0), \mathrm{MOPS}(21)$, $5,0 \mathrm{~mL} \cdot \mathrm{L}^{-1}$ da solução de sais e $1,0 \mathrm{~mL} \cdot \mathrm{L}^{-1}$ da solução de elementos traços descritas acima, $\mathrm{pH}$ ajustado em 7,2 $\pm 0,1$. Quanto às fontes de nitrogênio, um meio conteve $\left(\mathrm{em} \mathrm{g} \cdot \mathrm{L}^{-1}\right)$ somente lisina $(18,3)$ e o outro, lisina $(9,2)$ e glutamato $(9,4)$, mantendo-se o mesmo teor inicial de nitrogênio em ambos os meios. Os cultivos em frascos agitados foram realizados em mesa rotativa $(260 \mathrm{rpm}, 5$ $\mathrm{cm}$ de excentricidade, $28^{\circ} \mathrm{C}$ ), com amostragem em 24,48 e 72 horas. Os experimentos em biorreator convencional $(5 \mathrm{~L}$ de volume útil) foram realizados em batelada, com controles de temperatura $\left(28^{\circ} \mathrm{C}\right), \mathrm{pH}(6,8)$ e oxigênio dissolvido em $50 \%$ relativo à saturação, mantido por vazão de ar ajustada em 1 vvm e pela variação automática da velocidade de agitação (250 a 400 $\mathrm{rpm})$. O volume reacional foi de 1,5 L de meio e utilizou-se apenas um impelidor (tipo Rushton). Todos os cultivos foram realizados em duplicata. As amostras foram centrifugadas $\left(4^{\circ} \mathrm{C}, 11.000 \mathrm{~g}\right)$, separando-se a biomassa do sobrenadante. A biomassa foi expressa em $\mathrm{g} \cdot \mathrm{L}^{-1}$ de massa seca de células, determinada após lavagem do decantado, secagem (a $105^{\circ} \mathrm{C}$ por 24 horas) e pesagem em recipiente previamente calibrado. Com o sobrenadante foram determinadas as concentrações de maltose, lisina, glutamato, Hol, CefC e AC. O açúcar e os aminoácidos foram determinados por HPLC acoplado a um detector de índice de refração. Hol foi extraída do caldo fermentado com butanol (1:1) (KENING e READING, 1979) e sua concentração determinada por HPLC acoplado a um detector UV (LIRAS E MARTÍN, 2005). Em virtude da indisponibilidade comercial de CefC, este biocomposto foi determinado indiretamente por meio de bioensaio de difusão em ágar de acordo com método descrito por Liras e Martín (2005). Neste método utiliza-se cefalosporina C como composto padrão e Escherichia coli ESS 2235 como bactéria-teste, super sensível a antibióticos beta-lactâmicos. Ainda, as amostras foram previamente tratadas com penicilinase (Penase ${ }^{\circledR}$, Difco) para eliminar a penicilina $\mathrm{N}$, interferente na análise. AC foi determinado em espectrofotômetro UV-vis, após reação com imidazol, seguida de leitura do composto resultante da reação a $312 \mathrm{~nm}$, conforme método descrito em BIRD et al. (1982). As Equações Diferenciais 
Ordinárias (EDOs) dos modelos foram integradas utilizando-se o software livre Scilab (versão 5.4.1) e os parâmetros cinéticos e estequiométricos foram estimados utilizando-se o algoritmo de Marquardt de regressão não linear (MARQUARDT, 1963), a 95\% de grau de confiança, implementado em linguagem Fortran.

\section{RESULTADOS E DISCUSSÃO}

\subsection{Crescimento celular em diferentes fontes de carbono}

Os resultados de crescimento celular em frascos agitados utilizando-se como fontes de carbono maltose, lisina ou glutamato, individualmente, estão apresentados na Figura 1. Para o cultivo em maltose foi utilizada uma fonte inorgânica de nitrogênio $\left(\mathrm{NH}_{4} \mathrm{Cl}\right)$, considerando-se uma proporção $\mathrm{C}: \mathrm{N}$ compatível com a dos dois aminoácidos. $\mathrm{O}$ cultivo em glutamato do presente trabalho fez parte de uma série de experimentos anteriormente realizados utilizando-se este aminoácido em várias concentrações, com amostragem a cada 24 horas. Pode-se observar uma drástica queda da biomassa a partir de 24 horas (Figura 1C). Isto ocorreu porque, enquanto nos meios contendo maltose ou lisina os valores de $\mathrm{pH}$ mantiveram-se em torno de 7,0, em glutamato o $\mathrm{pH}$ atingiu valores próximos de 9,0. Ainda assim, mostrou-se que o glutamato é uma fonte apropriada para o crescimento celular, porém, sob controle adequado de $\mathrm{pH}$ durante o cultivo.

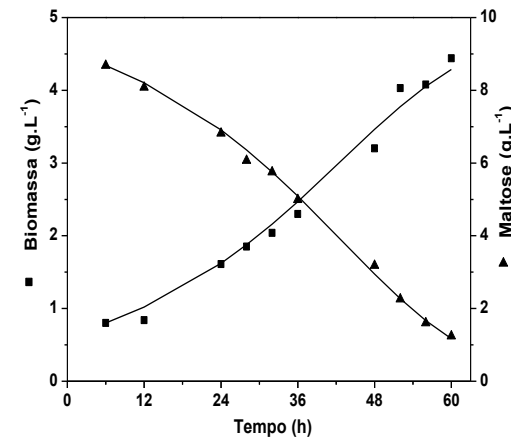

(A)

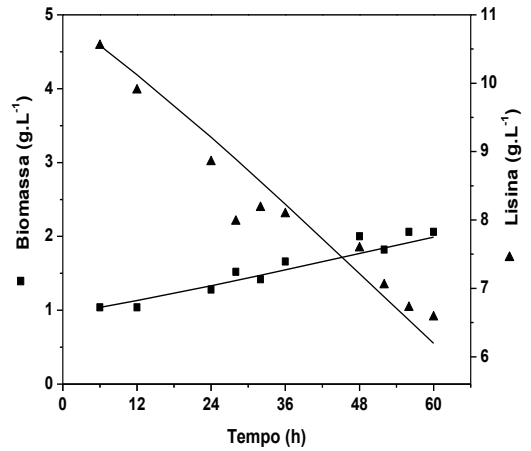

(B)

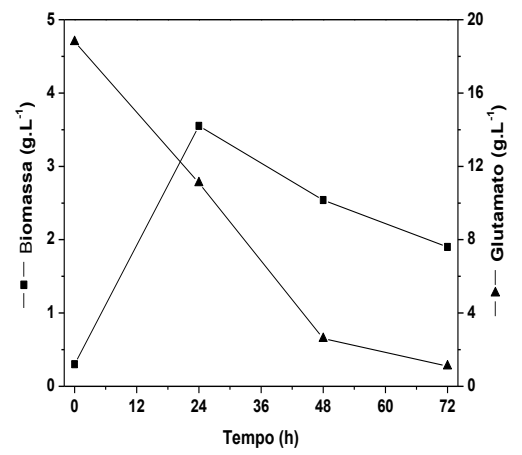

(C)

Figura 1 - Crescimento de Streptomyces clavuligerus ATCC 27064 em frascos agitados em meios contendo: maltose (A), lisina (B) e glutamato (C).

O modelo de Monod ajustou-se bem à cinética de crescimento em maltose e o modelo logístico foi o mais adequado ao crescimento em lisina. Os valores estimados de velocidade específica máxima de crescimento e a constante de Monod foram $\mu_{\text {máxMalt }}=0,065 \pm 0,005 \cdot\left(\mathrm{h}^{-1}\right) \mathrm{e}$ $\mathrm{k}_{\text {Malt }}=5,3 \pm 0,8\left(\mathrm{~g}_{\text {Malt }} \cdot \mathrm{L}^{-1}\right)$. Os parâmetros estimados para o modelo de velocidade específica de crescimento em lisina foram $\mu_{\text {máxLis }}=0,033 \pm 0,007\left(\mathrm{~h}^{-1}\right)$ e a constante do modelo logístico $\mathrm{k}_{\mathrm{Lis}}=$ $0,013 \pm 0,004\left(\mathrm{~L} \cdot \mathrm{g}^{-1} \cdot \mathrm{h}^{-1}\right)$, Os valores estimados de coeficiente de rendimento de substrato a células foram (em $\left.\mathrm{g}_{\text {cél }} \cdot \mathrm{g}_{\text {substrato }}{ }^{-1}\right) \mathrm{Y}_{\mathrm{X} / \mathrm{Malt}}=0,46 \pm 0,01$ e $\mathrm{Y}_{\mathrm{X} / \mathrm{Lis}}=0,23 \pm 0,02$. $\mathrm{O}$ coeficiente de rendimento de glutamato a células foi calculado para 24 horas de cultivo, resultando em $\mathrm{Y}_{\mathrm{X} / \mathrm{Glut}} \cong 0,4$, um valor da mesma ordem de grandeza do estimado para o crescimento em maltose.

\subsection{Produção de compostos bioativos}

Cultivo em maltose e lisina: O papel da lisina como estimulante da biossíntese de CefC tem sido bem reportado na literatura, uma vez que este aminoácido é convertido, via lisina 
aminotransferase, no ácido alfa aminoadípico, o qual compõe o tripeptídeo aminoadipil-cisteinilvalina (ACV), precursor de todos os antibióticos beta-lactâmicos (DEMAIN e VAISHNAV, 2006). Com base nesta informação, um meio quimicamente definido contendo maltose e lisina como fontes de carbono e energia e de nitrogênio foi empregado. Os dados experimentais estão apresentados no conjunto de gráficos da Figura 2. Embora o objetivo fosse a produção de CefC, foram obtidas concentrações deste biocomposto e de AC da mesma ordem de grandeza, entre 90 e $100 \mathrm{mg} \cdot \mathrm{L}^{-1}$. Sabe-se que as rotas biossintéticas destes compostos são totalmente independentes, todavia a produção de ambos ocorre de forma concomitante. Isto se deve ao fato de que as biossínteses de ambos são reguladas pelo mesmo elemento multifuncional ccaR (cephamycin and clavulanic acid Regulator), codificado pelo gene ccaR. Desta forma, a presença e a concentração de determinados nutrientes no meio de cultivo podem favorecer a produção de um ou outro composto, todavia obter altos níveis de um destes bioativos em detrimento do outro é muito difícil. Quanto a Hol, sua produção foi desprezível, cerca de $5 \mathrm{mg} \cdot \mathrm{L}^{-1}$.

Os dados apresentados no item 3.1 mostraram que a utilização de maltose ou lisina como fonte de carbono sustenta o crescimento de $S$. clavuligerus. A utilização conjunta de maltose e lisina, porém, resultou em perfis bem diferentes de crescimento e consumo dos substratos (Figura 2). Desta forma, no modelo matemático para este processo (Modelo 1) foi considerada a influência de ambos os compostos na velocidade de crescimento, os quais, porém, exercendo diferentes funções celulares, conforme cinética proposta por Megee (FREDRICKSON et al., 1970). Assim, maltose participa essencialmente como substrato para a formação de biomassa e lisina atua majoritariamente como fonte de manutenção celular. Esta proposta fundamentou-se no fato de que o catabolismo de lisina gera duas moléculas de acetil-coenzima A, geralmente metabolizadas através do ciclo de Krebs, a principal via de fornecimento de energia para as células em condições de aerobiose. Ainda, foi assumido que o consumo de lisina é dependente de sua concentração de acordo com uma cinética de saturação. Para a produção dos compostos bioativos (CefC e AC), adotou-se uma cinética totalmente associada ao crescimento, conforme evidenciado pelos dados experimentais. As EDOs do Modelo 1 são apresentadas a seguir:

$$
\begin{aligned}
& \mu_{I}=\mu_{\text {maxl }} \cdot \frac{C_{\text {Malt }}}{k_{\text {Malt } 1}+C_{\text {Malt }}} \cdot \frac{C_{\text {Lis }}}{k_{\text {Lisl }}+C_{\text {Lis }}} \\
& \frac{d C_{x}}{d t}=\left(\mu_{1}-k_{d 1}\right) \cdot C_{x} \\
& \frac{d C_{\text {malt }}}{d t}=-\frac{\mu_{1}}{Y_{\text {Xmalt } 1}} \cdot C_{x} \\
& \frac{d C_{\text {Lis }}}{d t}=-m_{\text {Lisl }} \cdot \frac{C_{L i s}}{k_{\text {Lisl }}+C_{\text {Lis }}} \cdot C_{x} \\
& \frac{d C_{C e f C}}{d t}=\alpha_{C e f C l} \cdot \mu_{1} \cdot C_{x} \\
& \frac{d C_{A C}}{d t}=\alpha_{A C l} \cdot \mu_{1} \cdot C_{x}
\end{aligned}
$$

Pode-se constatar pela Figura 2 o bom ajuste do Modelo 1 aos dados experimentais. Os parâmetros deste modelo estão apresentados na Tabela 1. O parâmetro estimado para a manutenção celular, $\mathrm{m}_{\text {Lis } 1}=0,058 \mathrm{~g}_{\text {Lis }} \cdot \mathrm{g}_{\text {cél }} \cdot \mathrm{h}^{-1}$, corresponde a $0,01 \mathrm{mols}_{\mathrm{ATP}} \cdot \mathrm{g}_{\text {cél }}{ }^{-1} \cdot \mathrm{h}^{-1}$, considerandose que a oxidação completa da lisina produz 32 ATPs $\left(\equiv 0,175 \mathrm{mols}_{\mathrm{ATP}} \cdot \mathrm{g}_{\mathrm{Lis}}{ }^{-1}\right)$. Stephanopoulos $e t$ al. (1998) coletaram dados de energia de manutenção para vários microrganismos em diferentes 
condições do cultivo e observaram uma ampla faixa de valores, de $10^{-3}$ a $1,9 \cdot 10^{-2} \mathrm{mols}_{\mathrm{ATP}} \cdot \mathrm{g}_{\text {cél }}{ }^{-1} \cdot \mathrm{h}^{-1}$, suportando, assim, o valor estimado no presente estudo.
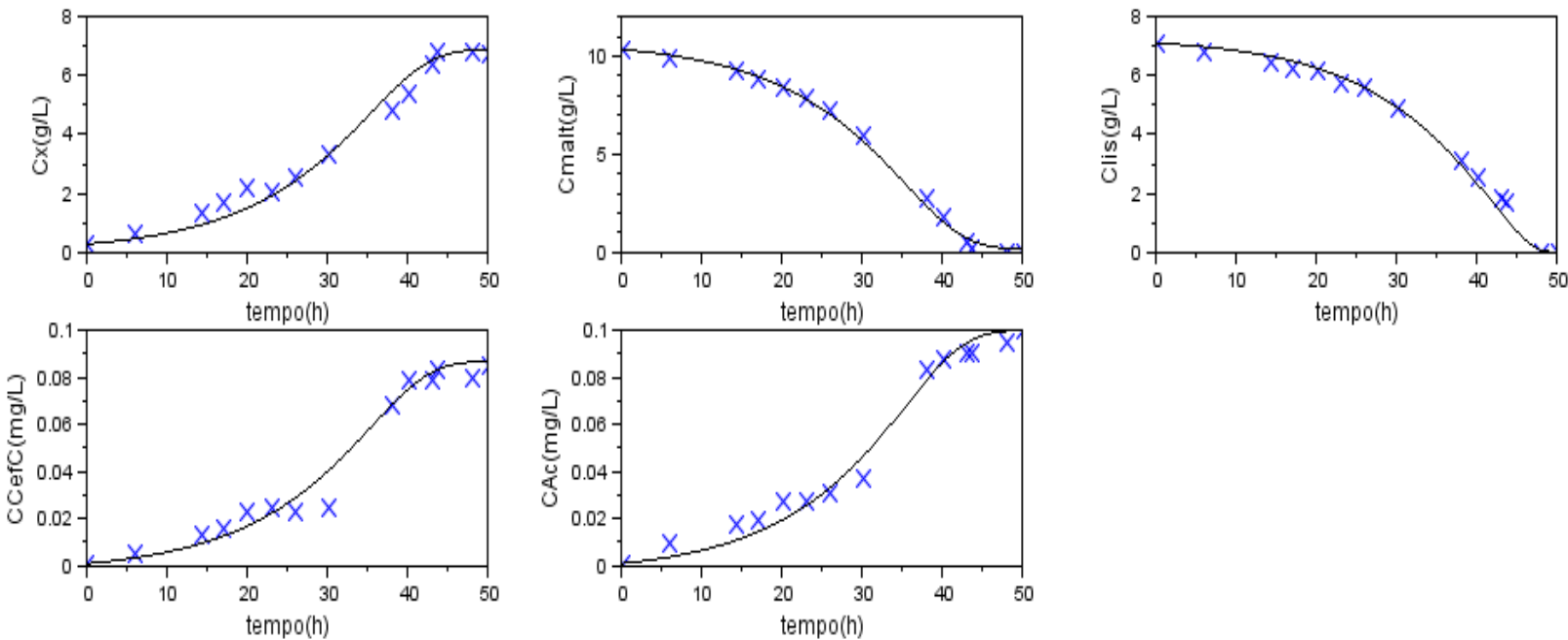

Figura 2 - Perfis de concentração de células (Cx), maltose (Cmalt), lisina (Clis), cefamicina C (CCefC) e ácido clavulânico (CAc) de cultivo em biorreator convencional operado em batelada ( $\times$ - dados experimentais; --- - ajuste do Modelo 1$)$.

Tabela 1 - Valores estimados dos parâmetros do Modelo 1

\begin{tabular}{|c|c|c|}
\hline Velocidade específica máxima de crescimento & $\mu_{\max 1}$ & $0,101 \pm 0,003\left(h^{-1}\right)$ \\
\hline Constante do modelo de Megee para maltose & $\mathrm{k}_{\text {Malt1 }}$ & $2,06 \pm 0,28\left(\mathrm{~g}_{\text {Malt }} \cdot \mathrm{L}^{-1}\right)$ \\
\hline Constante do modelo de Megee para lisina & $\mathrm{k}_{\text {Lis1 }}$ & $0,15 \pm 0,11\left(\mathrm{~g}_{\mathrm{Lis}} \cdot \mathrm{L}^{-1}\right)$ \\
\hline Constante de morte celular & $\mathrm{k}_{\mathrm{d} 1}$ & $0,0\left(\mathrm{~h}^{-1}\right)$ \\
\hline Coef. de rendimento de maltose a células & $Y_{\text {Xmalt1 }}$ & $0,630 \pm 0,005\left(\mathrm{~g}_{\text {Malt }} \cdot \mathrm{g}_{\text {cél }}{ }^{-1}\right)$ \\
\hline Coef. de manutenção celular pela lisina & $\mathrm{m}_{\text {Lis1 }}$ & $0,058 \pm 0,002\left(\mathrm{~g}_{\text {Lis }} \cdot \mathrm{g}_{\text {cél }}{ }^{-1} \cdot \mathrm{h}^{-1}\right)$ \\
\hline Coef. do modelo de Leudeking-Piret para CefC, associada ao crescimento & $\alpha_{\mathrm{CefC} 1}$ & $0,013\left(\mathrm{~g}_{\text {CefC }} \cdot \mathrm{g}_{\text {cél }}^{-1}\right)$ \\
\hline Coef. do modelo de Leudeking-Piret para AC, associada ao crescimento & $\alpha_{\mathrm{AC} 1}$ & $0,015\left(\mathrm{~g}_{\mathrm{AC}} \cdot \mathrm{g}_{\text {cél }}{ }^{-1}\right)$ \\
\hline
\end{tabular}

Cultivo em maltose, glutamato e lisina: O catabolismo da lisina ocorre via cadaverina, através da qual todo o nitrogênio do aminoácido é transaminado para alfa-cetoglutarato resultando em duas moléculas de glutamato (MADDURI et al., 1989). Assim, a adição de glutamato ao meio contendo lisina poderia suprir a demanda por nitrogênio do metabolismo primário, promovendo a diminuição do consumo de lisina via cadaverina e aumentando a disponibilidade do aminoácido para a biossíntese de CefC. Com base nesta suposição, utilizou-se um meio quimicamente definido contendo maltose, lisina e glutamato como fontes de carbono e energia e de nitrogênio visando um aumento da produção de CefC. Os resultados experimentais estão apresentados no conjunto de gráficos da Figura 3. Pode-se observar que esta estratégia não surtiu o efeito esperado, obtendo-se cerca de $65 \%$ menos $\mathrm{CefC}$ ou $\mathrm{AC}$ do que foi obtido destes compostos em meio contendo apenas maltose e lisina. Possivelmente a adição de glutamato alterou a regulação do metabolismo do nitrogênio diminuindo a produção destes bioativos. Um comportamento semelhante também foi observado por Romero et al. (1984) em meios sem lisina. Todavia, a combinação de maltose, glutamato e lisina resultou em uma alta concentração de Hol, $110 \mathrm{mg} \cdot \mathrm{L}^{-1}$, uma produção nunca relatada para a linhagem selvagem. 

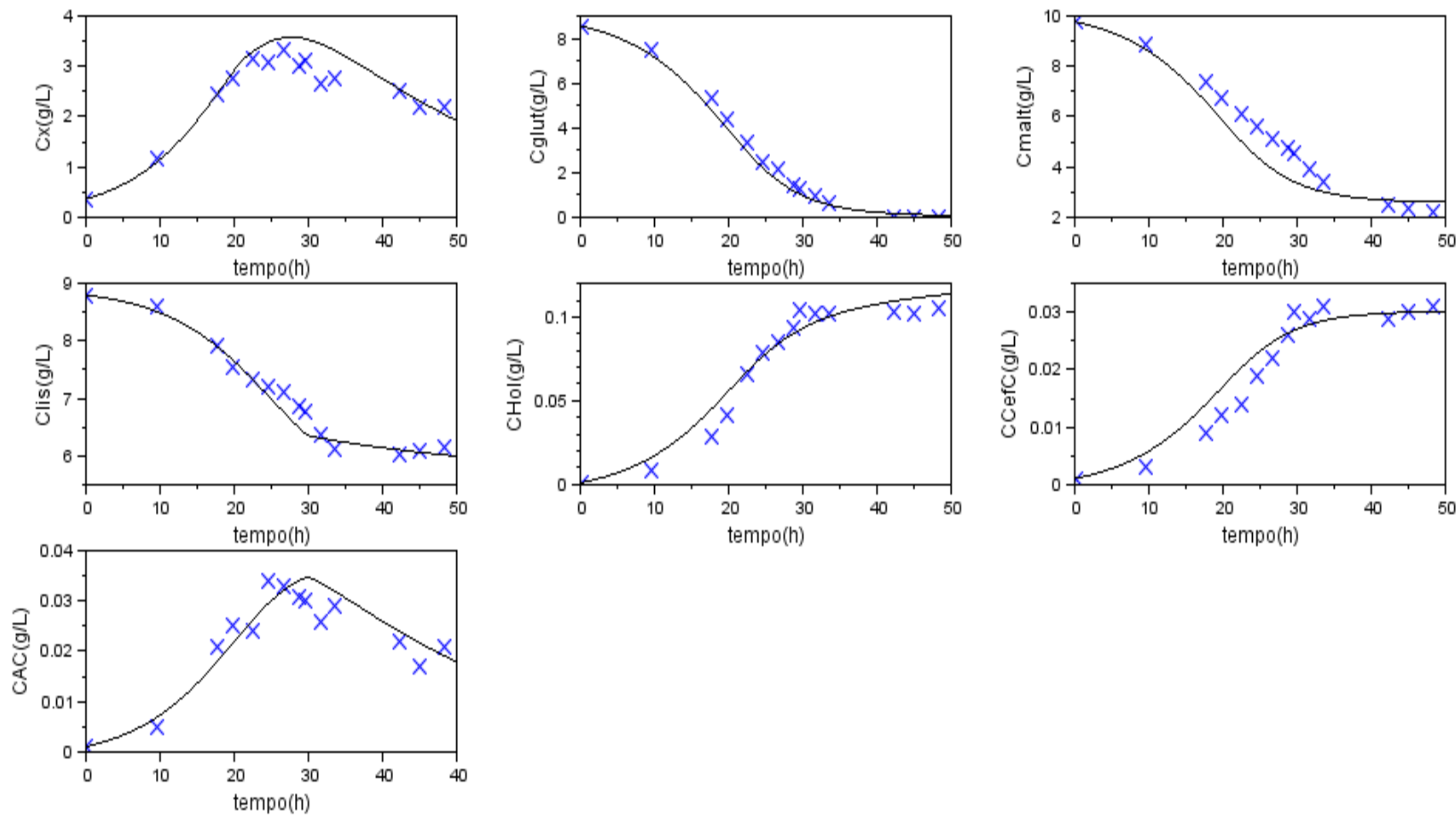

Figura 3 - Perfis de concentração de células $(\mathrm{Cx})$, glutamato (Cglut), maltose (Cmalt), lisina

(Clis), holomicina ( $\mathrm{CHol})$, cefamicina $\mathrm{C}$ (CCefC) e ácido clavulânico (CAc) de cultivo em biorreator convencional operado em batelada $(\times$ - dados experimentais; --- - ajuste do Modelo 2$)$.

De la Fuente et al. (2002) mostraram que mutantes de S. clavuligerus bloqueados em determinadas etapas da rota biossintética de AC produzem quantidades significativas de Hol. Os autores sugeriram que o acúmulo de intermediários da rota de AC direciona o metabolismo secundário para a produção de Hol. A alta produção de Hol pela linhagem selvagem obtida no presente estudo pode estar associada à inibição da produção de $\mathrm{AC}$ ocasionada pelo acúmulo de espécies nitrogenadas no meio de cultivo. O comportamento do processo permitiu propor um modelo (Modelo 2) no qual lisina, devido ao seu baixo consumo, não influencia diretamente no crescimento, atuando apenas na manutenção celular. O glutamato e a maltose, por sua vez, foram considerados determinantes da velocidade de crescimento assumindo-se a cinética de Megee e para a produção dos biocompostos foram assumidos o modelo totalmente associado ao crescimento para CefC ou AC e o modelo parcialmente associado ao crescimento de Leudeking e Piret para Hol (FREDRICKSON et al., 1970). As EDOs do Modelo 2 são apresentadas a seguir:

$$
\begin{aligned}
& \mu_{2}=\mu_{\max 2} \cdot \frac{C_{\text {Malt }}}{k_{\text {Malt } 2}+C_{\text {Malt }}} \cdot \frac{C_{\text {Glut }}}{k_{\text {Glut } 2}+C_{\text {Glut }}} \\
& \frac{d C_{x}}{d t}=\left(\mu_{2}-k_{d 2}\right) \cdot C_{x} \\
& \frac{d C_{\text {Glut }}}{d t}=\frac{-\mu_{2}}{Y_{\text {XGlut } 2}} \cdot C_{x} \\
& \frac{d C_{\text {Malt }}}{d t}=\frac{-\mu_{2}}{Y_{\text {XMalt } 2}} \cdot C_{x} \\
& \frac{d C_{\text {Lis }}}{d t}=-m_{\text {Lis } 2} \cdot \frac{C_{\text {Lis }}}{k_{\text {Lis } 2}+C_{\text {Lis }}} \cdot C_{x}
\end{aligned}
$$


$\frac{d C_{H o l}}{d t}=\alpha_{H o l 2} \cdot \mu_{2} \cdot C_{x}+\beta_{H o l 2} \cdot C_{x}$
$\frac{d C_{C e f C}}{d t}=\alpha_{C e f C 2} \cdot \mu_{2} \cdot C_{x}$
$\frac{d C_{A C}}{d t}=\alpha_{A C 2} \cdot \mu_{2} \cdot C_{x}-k_{d A C 2} \cdot C_{A C}$

O Modelo 2 ajustou-se de maneira bem satisfatória aos dados experimentais. Com relação ao cultivo em meio contendo apenas maltose e lisina, a velocidade específica máxima de crescimento estimada foi cerca de 2,5 vezes maior, justificada pela ambientação prévia do microrganismo em glutamato durante a preparação do inóculo principal. Entretanto, o acúmulo de biomassa foi 50\% menor. Isto pode ser explicado pela baixa resistência de $S$. clavuligerus a Hol, mais evidente em concentrações do biocomposto acima de $60 \mathrm{mg} \cdot \mathrm{L}^{-1}$, observando-se o dobro da taxa de morte celular e velocidade de manutenção por lisina cerca de $85 \%$ menor. Também, acredita-se que esta toxicidade exercida por Hol acarretou uma maior demanda energética do microrganismo, de forma que o coeficiente de lisina para a manutenção celular estimado no Modelo 2 foi cerca de 3 vezes maior que o ajustado para o Modelo 1. Os parâmetros do Modelo 2 estão na Tabela 2.

O complexo metabolismo de $S$. clavuligerus é extremamente susceptível a alterações no ambiente. Condições de meio inicialmente propostas para melhorar a produção de CefC, por ex., não surtiram o efeito esperado, porém, mostraram-se adequadas à produção de altas concentrações de Hol. Os modelos cinéticos propostos, fundamentados em informações bioquímicas e metabólicas, refletiram muito bem o comportamento dos processos investigados.

Tabela 2 - Valores estimados dos parâmetros do Modelo 2

\begin{tabular}{|c|c|c|}
\hline Velocidade específica máxima de crescimento & $\mu_{\max 2}$ & $0,242 \pm 0,049\left(\mathrm{~h}^{-1}\right)$ \\
\hline Constante do modelo de Megee para maltose & $\mathrm{k}_{\text {Malt2 }}$ & $4,12 \pm 4,24\left(\mathrm{~g}_{\text {Malt }} \cdot \mathrm{L}^{-1}\right)$ \\
\hline Constante do modelo de Megee para glutamato & $\mathrm{k}_{\mathrm{Glut} 2}$ & $2,54 \pm 1,35\left(\mathrm{~g}_{\mathrm{Glut}} \cdot \mathrm{L}^{-1}\right)$ \\
\hline Constante de morte celular & $\mathrm{k}_{\mathrm{d} 2}$ & $0,023 \pm 0,001\left(\mathrm{~h}^{-1}\right)$ \\
\hline Coef. de rendimento de glutamato a células & $\mathrm{Y}_{\mathrm{XGlut} 2}$ & $0,064 \pm 0,01\left(\mathrm{~g}_{\text {Glut }} \cdot \mathrm{g}_{\text {cél }}^{-1}\right)$ \\
\hline Coef. de rendimento de maltose a células & $\mathrm{Y}_{\mathrm{XMalt2}}$ & $0,79 \pm 0,02\left(\mathrm{~g}_{\text {Malt }} \cdot \mathrm{g}_{\text {cél }}^{-1}\right)$ \\
\hline Coef. de manutenção celular pela lisina & $\mathrm{m}_{\text {Lis2 }}$ & $0,175 \pm 0,076\left(\mathrm{~g}_{\text {Lis }} \cdot \mathrm{g}_{\text {cél }}{ }^{-1} \cdot \mathrm{h}^{-1}\right)$ \\
\hline Coef. de saturação da velocidade de manutenção & $\mathrm{k}_{\mathrm{Lis} 2}$ & $24,24 \pm 12,44\left(\mathrm{~g}_{\mathrm{Lis}} \cdot \mathrm{L}^{-1}\right)$ \\
\hline Coef. do modelo de Leudeking-Piret para Hol, associada ao crescimento & $\alpha_{\mathrm{Hol} 2}$ & $0,016\left(\mathrm{~g}_{\text {Hol }} \cdot \mathrm{g}_{\text {cél }}^{-1}\right)$ \\
\hline Coef. do modelo de Leudeking-Piret para Hol, não associada ao crescimento & $\beta_{\mathrm{Hol} 2}$ & $0,0002\left(\mathrm{~g}_{\mathrm{Hol}} \cdot \mathrm{g}_{\text {cél }}^{-1} \cdot \mathrm{h}^{-1}\right)$ \\
\hline Coef. do modelo de Leudeking-Piret para CefC, associada ao crescimento & $\alpha_{\mathrm{CefC} 2}$ & $0,0052\left(\mathrm{~g}_{\mathrm{CefC} C} \cdot \mathrm{g}_{\text {cél }}{ }^{-1}\right)$ \\
\hline Coef. do modelo de Leudeking-Piret para AC, associada ao crescimento & $\alpha_{\mathrm{AC} 2}$ & $0,0068\left(\mathrm{~g}_{\mathrm{AC}} \cdot \mathrm{g}_{\mathrm{cél}}^{-1}\right)$ \\
\hline Constante de degradação de AC & $\mathrm{k}_{\mathrm{dAC} 2}$ & $0,04\left(\mathrm{~h}^{-1}\right)$ \\
\hline
\end{tabular}

\section{Referências}

BIRD, A. E.; BELLIS, J. M.; GASSON, B. C. Spectrophotometric assay of clavulanic acid by reaction with imidazole. Analyst, v. 107, n. 1279, p. 1241-1245, 1982.

DE LA FUENTE, A.; LORENZANA, L. M.; MARTÍN, J. F.; LIRAS, P. Mutants of Streptomyces clavuligerus with disruptions in different genes for clavulanic acid biosynthesis produce 
large amounts of holomycin: possible crossregulation of two unrelated secondary metabolic pathways. J. Bacteriol., v. 184, p. 6559-6565, 2002.

DOMINGUES, L. C. G.; TEODORO, J. C.; HOKKA, C. O.; BADINO, A. C.; ARAUJO, M. L. G. C. Optimisation of the glycerol-to-ornithine molar ratio in the feed medium for the continuous production of clavulanic acid by Streptomyces clavuligerus. Biochem. Eng. J., v. 53, p. 7-11, 2010.

FREDRICKSON, A. G.; MEGEE, R. D.; TSUCHIYA, H. M. Mathematical models for fermentation processes. Adv. Appl. Microbiol., v. 13, p. 419-465, 1970.

KENING, M.; READING, C. Holomycin and an antibiotic (MM 19290) related to tunicamycln, metabolites of Streptomyces clavuligerus. J. Antibiot., p. 549-554, 1979.

LEITE, C. A.; CAVAlLIERI, A. P.; ARAUJO, M. L. G. C. Enhancing effect of lysine combined with other compounds on cephamycin C production in Streptomyces clavuligerus. BMC Microbiol., v. 13, n. 296, 2013.

LI, B.; WALSH, C. T. Identification of the gene cluster for the dithiolopyrrolone antibiotic holomycin in Streptomyces clavuligerus. PNAS, v. 107, n. 46, p. 19731-19735, 2010.

LIRAS, P.; MARTÍN, J. F. Methods in biotechnology. New Jersey: Humana Press v. 18, p. 149$163,2005$.

LIRAS, P.; MARTÍN, J. F. Gene clusters for beta-lactam antibiotics and control of their expression: why have clusters evolved, and from where did they originate? Int. Microbiol., v. 9, p. 9-19, 2006.

MADDURI, K.; STUTTARD, C.; VINING, L. C. Lysine catabolism in Streptomyces spp. is primarily through cadaverine: $\beta$-lactam producers also make alpha-aminoadipate. $J$. Bacteriol., v. 171, n. 1, p. 299-302, 1989.

MARQUARDT, D. W. An algorithm for least-squares estimation of nonlinear parameters. J. Soc. Ind. App. Math., v. 11, n. 2, p. 431-441, 1963.

NÁRDIZ, N.; SANTAMARTA, I.; LORENZANA, L. M.; MARTÍN, J. F.; LIRAS, P. A rhodanese-like protein is highly overrepresented in the mutant $S$. clavuligerus oppA2::aph: effect on holomycin and other secondary metabolites production. Microbiol. Biotechnol., v. 4, n. 2, p. 216-225, 2011.

OLIVA, B.; O’NEILL, A.; WILSON,J.M.; O’HANLON, P.J.; CHOPRA, I. Antimicrobial properties and mode of action of the pyrrothine holomycin. Antimicrob. Agents Chemother., v. 45, n. 2, p. 532-539, 2001.

ROMERO, J.; LIRAS, P.; MARTIN, J. F. Dissociation of cephamycin and clavulanic acid biosynthesis in Streptomyces clavuligerus. Appl. Microbiol. Biotechnol., v. 20, n. 5, p. 318325, 1984.

STEPHANOPOULOS, G. Metabolic fluxes and metabolic engineering. Metabolic Engineering. v. 1, p. 1-11, 1999.

TEODORO, J. C.; BAPTISTA-NETO, A.; ARAUJO, M. L. G. C.; HOKKA, C. O.; BADINO, A. C. Influence of glycerol and ornithine feeding on clavulanic acid production by Streptomyces clavuligerus. Braz. J. Chem. Eng., v. 27, n. 4, p. 499-506, 2010. 